\title{
Relationship of Budgeting and Accounting: Implication for Public Policy
}

\author{
by \\ James P. Trebby \\ Marquette University \\ Relmond P. Van Daniker \\ University of Kentucky
}

\begin{abstract}
Budgetary comparisons in the financial reporting of state and local government entities have developed over a number of years. However, the relationship between budgeting and the budgetary process and accounting and financial reporting in the governmental area has long been a subject of controversy. Some reasons behind this controversy include the following. First, budgeting is a planning process while accounting records the actual events; therefore budgeting is prior to the actual events while accounting is after the fact. Second, the budget is the policy statement of the government while the financial reports are the results of the policy.

Since the budget is part of the planning activities, some accountants believe that the budget is an internal document and not necessary for external reporting. Some budgeting officials maintain that legal compliance is the only required report and external financial reporting, except on the legal compliance basis, is not necessary. These proponents argue that since the appropriation is the law, any external financial reporting should be based on the law and the users of financial information are primarily concerned with the governmental entity's compliance with the law. Further, the suggestion is made that converting to any other format, i.e., generally accepted accounting principles, might mislead these users.

The purpose of this article is to discuss the relationship between budgeting and accounting and the need for reporting on the budget to actual comparison in terms of the public policy. Comparison information is necessary for both internal comparisons and external reporting that lead to policy decisions. However, both internal and external reporting are hampered by differences in perspectives, philosophies, bases and definition of the entity between budgeting and accounting.
\end{abstract}

Budgeting and Accounting in the Management of Government

As an overall statement, budgeting is a resource allocation mechanism, while accounting is a process of classifying, recording, summarizing and analyzing the actual use of resources by an economic entity. While the two process involve different objectives, both are necessary in the management of government. Budgeting and accounting are involved in the management and operation of government on both the internal and external level.

Budgeting raises key issues for internal decision-makers indicating the choices to be made in distributing limited resources. The budgeting process and the subsequent appropriation provides the legal basis for the expenditure of funds and fiscal accountability. The budgeting process facilitates the delega- 
tion of operating and financial authority and responsibility, while providing some basis for central control and oversight. In addition, budgeting offers the potential for periodic reconsideration of governmental purposes and objectives and fosters comparative evaluation of different purposes and programs in relation to each other and their respective costs.

Each government must make its own resource allocation choices and design a budgeting system according to the particular circumstances of the entity. However, a failure to integrate accounting information into the budgetary process would deprive decision-makers of data essential in weighing alternative resource allocations. Also, it is virtually impossible to measure results against plans without accounting data. Consequently, in order for public policy to be effective, budgeting and accounting must be integrated.

Unfortunately, the accounting data will not be available in sufficient time to assist in the preparation of the current fiscal year's budget because the budget, a planning tool, is prepared in advance of the current year, However, for public policy to be effective, the integration is necessary as the budget is implemented. As implementation occurs, the accounting information should provide the comparison of the actual results to the plan, or budgeted activities. These results can then be used in the planning process for the next budget.

In addition to internal management decisions, budgeting and accounting are related in terms of financial reporting for external users. These users range from the individual taxpayers, legislators, employee unions, and bond rating agencies, to the investor in government securities.

In conjunction with the State Government Accounting Project, a survey of the users of state and local financial reports was developed. A questionnaire was distributed to 4,000 individuals identified as either users or potential users of governmental financial reports. The individual were representative of all 50 states and over 1,900 usable responses were received.

The objective of the study included: (1) evaluating the usefulness of general purpose financial statements; (2) examining the respondents' concern with respect to current reporting practices; and (3) comparing the responses of the users relative to state versus local reporting. The users were divided into four groups: (1) executive branch, (2) legislative branch, (3) financial community, and (4) various public interest groups, including political subdivisions.

The most interesting result of this study for this article was the response to a question regarding the usefulness of financial statements. Overall, the Statement of Revenues and Expenditures - Budget to Actual, was considered the most important financial statement at both the state and local levels. This financial statement was rated higher than any other financial statement by each group of respondents.

The inference to be drawn from these responses can be debated. A possible inference is that the respondents might not prefer any financial reports and the selection of the budget comparison is the selection of the best of the worst. There are obvious delays in preparing the budgetary comparison for external users so that the value of the statement may be debated. Additionally, the respondents were not given innovative reports to consider and, perhaps, new and improved financial statements may be more useful than those currently published. Given these considerations, the bottom line remains that the users of financial statements need budgetary comparisons. To argue that these statements are not necessary for external users and are only internal 
documents does not seem justified.

Overview of Budgeting

Budgeting as an internal management tool evolved into an executive budget in the early part of this century. A control emphasis was installed in the budget process by line-items of expenditures. The executive branch received a detailed breakdown by personal services, operation costs, and capital costs. If the appropriation was made in this manner the budgeting process and accounting system would be consistent as long as the basis of accounting was the same as the basis of budgeting.

A line-item budget and appropriation focuses on the agency or department spending funds with little consideration of the function of the agency. This spending philosophy was changed with the recommendations of the Hoover Commission. The Commission's Report stated that a budgetary process should focus on:

...the general character and relative importance of the work to be done, or upon the services to be rendered, rather than upon the things to be acquired, such as personal services, supplies, equipment, and so on. These latter objects are, after all, only the means to an end. The all important thing in budgeting is the work or services to be accomplished, and what that work or service will cost. (3)

The recommendation of the Hoover Commission spurred action in the states to a performance-budgeting concept. Critics of the line-item budget argue that this method encourages spending rather than economizing. Line-item budgets encourage spending the entire appropriation whether it is needed or not and the manager has performed adequately as long as spending is kept within budgetary limitations. Since legislators often base subsequent appropriations on prior expenditures, a manager's budget may be reduced if he spends less than what he requested in a given year. Expenditures in the performance budget are based on measurable performance on activities and work programs. Instead of looking merely at how much was spent, performance evaluation focuses on dollar and activity standards.

Conceptually, a performance budget reduces the budgetary control emphasis by: (1) a loosening of central control over inputs, (2) primary reliance on internal rather than external control, (3) a reduction of itemized detail in the budget and appropriations, (4) a shift from budgetary to other administrative controls, (5) the use of objective measurements, and (6) the regular use of post audits and post controls.

However, the practice of budgeting is evolutionary rather than revolutionary and change to a new approach was very slow. There was resistance to decentralizing the control over inputs and even when the performance budget was used, the underlying focus continued to be the line-item budget.

The concept of a performance budget gave way to planning- programmingbudgeting systems (PPBS) and more recently to zero-based budgeting (ZBB). The emphasis of PPBS is planning while attention is given to the objectives of government. In addition, there is consideration of alternative methods for achieving these objectives. $\mathrm{ZBB}$ is an attempt to justify programs from a zero base and continues the evaluation of the objectives of government.

From the accounting viewpoint, as the budgeting philosophy changed, the accounting for the budget should have also been changed. However, the change in 
the accounting system was not a rapid as in the budgeting area. Whereas budgeting is a planning and control process which involves certain assumptions and preparation of budget estimates, the accounting system changes involve changing the forms, accounting classifications, payroll allocations, and the financial reports. These changes involve a considerable amount of time and effort as well as an extensive educational program. These changes can stretch over several years and cost several million dollars. For example, the State of Kentucky has been in the process of changing its accounting system for over three years and has already spent several million dollars. Other states are in basically the same situation in making changes in their accounting systems.

Given the problems in changing the accounting system to accommodate different budget philosophies, decisions relative to public policy are made more difficult. The information may not be available to relate the actual results with the planned activities. However, since the decisions will be made with little or no accounting information, public policy may be established without sufficient information.

Budgetary Reforms and Accounting Systems

In this section, some of the problems of relating budgetary reforms and accounting system changes will be discussed. Two budgetary types were selected as examples of the problems.

A. Planning, Program Budgeting System (PPBS) - A PPB System generally includes: (1) budgeting by program or a combination of programs and items of expenditure; (2) explicit statement of governmental goals and program objectives; and (3) a system for evaluating programs or activities. A PPBS is a continuation of the performance budgeting approach with an explicit statement of the goals and objectives.

An essential element in effective utilization of PPBS is the accounting system. As E. L. Enke notes:

The whole point of accounting systems is that they exist to furnish data for decision models. Failing to integrate with the accounting information system deprives PPBS of essential data. If the cost categories used by the financial management system are not consistent with those used by the budgetary system, the data collected may have little relevance for planning and programming. It will be difficult to compare plans with results. One of the first problems PPB poses for the accountant is the need to restructure financial information for its purposes.

John Haldi and Associates reached similar conclusions regarding budgetary reform and accounting in a National Association of State Budget Officers' commissioned study. They concluded that the inability of state government accounting systems to reflect financial information in a compatible perspective was a major contributing factor to failures in restructured budgetary practices.

One of the potential problems in PPBS is in defining the program at a level above the organizational structure. For example, a program entitled "Public Safety" could be established. This program could include activities such as state police, emergency preparedness, and some activities in Human Resources or Social Services. These activities, however, could be in different 
departments or agencies within the government.

There are several problems if a program is defined at a level above the organizational structure:

1. The outcome or results of the various activities will be comingled, at best, and nonexistent, at worst.

2. In the example, no individual would be ultimately responsible for the activities of the program. The various activities are the responsibility of different individuals and no one may be in a position to coordinate the various activities to achieve the objectives or goals of the Public Safety program.

3. If the appropriation is made to the program, legislative control is basically nonexistent because no individual is responsible for the program.

4. The accounting system will probably not record the results of the program in part because no one is responsible for the program. Unless someone is responsible for the program, there will be little interest in changing the present system to capture the information. In addition, there will be little interest in developing the measurement criteria for the program.

Thus, a program which is conceptually valid will exist for which no one is in charge and which the legislature does not control. There are, at least, three alternatives for solving this problem:

1. Reorganize the structure of government to create a cohesive Public Safety agency or department. This solution is probably the best approach but may be politically infeasible. The vested interests in keeping the activities in the organizational structure that exists may preclude substantial reorganization.

2. Redefine the programs that will be used. This solution somewhat violates the conceptual idea of PPBS, but would ameliorate substantual changes in the accounting system.

3. Maintain the present structure both in terms of organization and accounting and use a cross-walk system to integrate the planning, control, and management functions. Some states used this approach to maintain a line-item organization and accounting approach while aggregating to a program budget.

The State of Kentucky changed to a program budget from a line-item budget in the 1970's. In making the change, the three alternatives were considered and the pros and cons evaluated. Alternative 1 was rejected because of the political ramifications. The vested interest in the present organizational structure would not permit total reorganization. Some reorganization of state government was conducted but not enough to create program type departments. Alternative 3 was rejected because the perception of most employees is that PPBS does not exist if it appears that a line-item structure is present. If the budgeting system is going to impact behavior, the employees must perceive that there is a change in the budgeting philosophy.

Alternative 2 was the method selected to implement PPBS in Kentucky. The decision was made that the definition of a program would not be larger than the department. An individual was designated as ultimately responsible for the 
program. This decision was mutually agreed to by the budget director and the head of the accounting department. In reaching this agreement, the accounting system was modified to capture the program information and an attempt was made to record the outputs of the programs. Thus, the objective of the program budgeting remained but the process was altered so that the actual results could be compared with the budget.

B. Zero-Based Budgeting (ZBB) - The National Association of State Budget Officers' defined ZBB as:

... a method which formally considered reduced levels of expenditure rather than merely increases above current expenditure levels. The distinctive purpose of $\mathrm{ZBB}$ is to determine whether each activity warrants continuation at its current level or at a different level, or should be terminated. The ZBB format provides for the submission of budget requests of alternative funding levels, and for the priority ranking of activities in successively increasing levels of funding, starting from a level significantly below the current level.

ZBB is another in the budgetary attempts to focus on the outputs of governments rather than the inputs. The process involves three basic steps:

1. Identification of decision units through which budget requests can be prepared.

2. Preparation of decision packages at alternative spending levels.

3. Ranking the various decision packages by management.

Decision units may be program, function, organizational units or any elements which can be isolated for analysis and decision-making. After the decision units are determined, the alternative decision packages are developed. These decision packages should, theoretically, be prepared from a zero-base, but practically are developed as a percentage of current funding levels.

After the decision packages have been developed they must be ranked. The ranking of the decision packages is normally performed by the managers of the decision units within a specific organizational structure. The packages selected are then related to the funds available. Once the base level is funded, then the incremental activities can be selected based on the ranking by the managers.

ZBB was much ballyhooed as a new approach to budgeting by the Carter Administration; however, it was attempted in the U.S. Department of Agriculture in the early $1960^{\prime} \mathrm{s} .7^{\prime}$ The method proved to be too time consuming at USDA and had relatively little pay-off in better decisions. Three common criticisms of $\mathrm{ZBB}$ are:

1. If all the decision packages were reviewed and ranked against all others as they went through the review process, ZBB would be caught in a deluge of paper. For example, in Wilmington, Delaware, the amount of paperwork and time committed to the budget process was substantially increased (perhaps doubled). 8

2. Although the assumption of $\mathrm{ZBB}$ is that the decisions start at a zero base, the practical problems prevent starting at zero. Normally, a base is arbitrarily established as a percentage of the previous 
appropriations (e.g., 80 to 90 percent). Managers then concentrate their review on the decision packages that are not included in the established base. Thus, the objective of a zero-based review is eliminated by starting at a percentage of the previous appropriations.

3. Program"managers rank the decision packages and can subvert the system by including pet programs within the base. Politically popular decision packages are then given a low priority with the expectation that they will be approved anyway. Thus, the managers have achieved their objectives in having all of their decision packages approved.

ZBB has not achieved much success in government and the criticisms mentioned may have been sufficient to reduce the acceptance. There is, however, a fourth problem with $\mathrm{ZBB}$, which has received little recognition. In developing the various decision packages, there was little consideration of changing the accounting system to either account for the costs of the decision packages or to capture the outputs of the decision packages.

ZBB was, perhaps, not viable long enough to consider the accounting ramifications. However, without information concerning the actual cost of the decision packages and outputs, there could not be a budgetary comparison. Redesigning the accounting system to generate information on decision packages would be difficult. Since the decision packages may not be organizationally separate, developing accounting information for each decision package would require a systems change. In addition, since the various decision packages would change in the next period, subsequent and constant accounting system changes would be impossible. Simply stated, ZBB is not viable, irrespective of other criticism, because the accounting system could not be changed fast enough to provide information for budgetary comparisons as the budget was implemented. Without these comparisons, public policy is made almost in a vacuum. This approach is acceptable only for a short period of time. After that, the budgetary process is, of necessity, changed because the politicians have to answer to the voters about the cost of services provided.

External Reporting of Budgetary/Accounting Relationships

The discussion of the budgetary/accounting relationships of PPBS and ZBB related primarily to the internal reporting and the oversight of the legislators. Another dimension of this relationship is the need for external reporting. As indicated in the User Survey of the State Accounting Project, the budgetary comparison was considered the most useful financial report.

The NCGA in Statement \#1, identified a dual dimension of the external reporting of governmental accounting.

A governmental accounting system must make it possible both: (a) to present fairly and with full disclosure the financial position and results of financial operations of the funds and account groups of the governmental unit in conformity with generally accepted accounting principles; and (b) to determine and demonstrate compliance with finance-related legal and contractual provisions. 9

Although the User Survey indicated that the users want a budget to actual statement, the dual objectives of the governmental accounting system present 
some problems for the preparers of this statement. For example:

1. The budgetary entity and the accounting entity probably will not be identical. With the promulgation of Statement \#3, requiring the inclusion of some entities that were not previously part of the financial statements, this problem will be substantially increased. For example, college and universities, housing authorities and school boards may be included in the reporting entity. These entities may or may not be included fully or even partially in the budgetary entity.

2. Different bases of accounting are used in budgeting accounting, and financial reporting. The cash basis may be used in the budgeting process, while in accounting, the modified accrual basis is used for governmental funds and the accrual basis is used for proprietary funds.

3. The perspective of fund entity, organizational structure, and program structure may be different in the budgeting and accounting areas.

Since present governmental practice requires not only recording and reporting transactions in conformity with the legally-adopted budget but also in accordance with GAAP-based standards, a dilemma exists for both the preparers and the users of the information. The differences between the two approaches present several alternatives ranging from maintaining two sets of records to presenting financial statements on a budget basis and GAAP-basis with a reconciliation statement provided for the differences.

The purpose of the Statement of Revenues and Expenditures - Budget to Actual is to afford the readers an opportunity to determine conformance with the budget. In meeting this objective, the better approach would seem to be financial statements on both bases with a reconciliation for the differences. This type of statement would provide the users information not only on budgetary conformance but also of the differences of budget to GAAP. This latter information is necessary if financial statements are published that are not consistent with the budget basis. Maintaining two sets of records, one on the budget basis and another on the GAAP basis, would not provide the same comprehensive information. A reconciliation statement was recommended in NCGA Interpretation \#10 "State and Local Government Budgetary/Reporting."10

\section{Conclusion}

The adversarial relationship between budgeting and accounting which was noted earlier has continued with the publication of Statement \#1 by NCGA. In the 1968 publication of Governmental Accounting, Auditing, and Financial Reporting (GAAFR), Principle \#l stated that the accounting system must both prepare financial statements in accordance with (a) legal compliance and (b) GAAP basis.11 Statement \#1 reversed the order of the presentation by listing (a) GAAP and (b) legal compliance.

The reverse of the order of presentation in statement \#1 prompted some accountants to suggest that legal compliance is now secondary to GAAP basis. They point to a principle of law that indicates if you do not mean a change then the same language should be used. By reversing the order, the implication is that NCGA downgraded legal compliance reporting below GAAP basis. The practical ramifications of this presumed changed is an attempt to force the accounting system to prepare GAAP statements and that a secondary schedule be 
prepared on the legal compliance basis. This approach is just the opposite of that practiced after the 1968 GAAFR. NCGA, for its part, indicated that it did not intend a change by noting that the principle requires both reports be prepared.

The budgeting officials may not consider this to be a significant problem as long as a budgetary report is prepared at some time. However, the reports that are distributed on a widespread basis are the GAAP basis statements. These reports may be significantly different from the budgetary comparisons and this may produce numerous questions among the users. Rather than answering the questions, a better approach would be for the accountants and budgeteers to cooperate in the development of a financial statement format which would attempt to answer the questions that would be asked.

The suggestion for those involved in the budget process to work with the accountants should not be interpreted to mean that budgeting is considered second to accounting. To the contrary, budgeting is a legislative and executive prerogative which lies outside the purview of accounting. However, the failure to work with the accountant and the accounting system in developing the budget is counter productive.

1. If the actual results are not compared with the budget, public policy decisions will be made without adequate information. Since the assumption is made that public policy decisions should be made with as much information as possible, public policy suffers without the comparison.

2. The examples of PPBS and $\mathrm{ZBB}$ presented indicate that budgetary reform must give consideration to changes in the accounting system. If the accounting changes are not made, the budgetary reform will be ineffective.

3. The financial report that the majority of users want to see is the Revenue and Expenditures - Budget to Actual comparison. If the users want this information, failure to relate the budget to actual is inadequate reporting.

Given that the comparison between the budget and actual will be presented, it is in the interest of both the budgeteers and accountants to design the best possible format. Since there are numerous differences between budgeting and accounting, the recommended approach would be to prepare two sets of financial statements--a budget to actual statement on the budgetary basis, as well as the financial statements on a GAAP basis. A reconciliation statement can then be prepared to explain the differences between the budgetary basis and GAAP.

These suggestions are made in the hope that it is clear that public policy decisions are not served by fragmented information and parochial perspectives. Accountants should not attempt to dictate budgeting policy because it is a legislative and executive prerogative. However, budgeteers must work with the accountants to implement accounting system changes to accommodate budgetary reform. A cooperative spirit, in spite of numerous differences in budgeting and accounting, is the best approach to provide information for effective public policy decisions.

\section{FOOTNOTES}

1 The State Government Accounting Project was a six-year research effort to 
develop preferred accounting practices for state governments. The recommended practices have been submitted to the National Council on Governmental Accounting for consideration as statements of generally accepted accounting principles for governmental entities.

2 Relmond P. Van Daniker and Richard Maschmeyer, "Financial Information Needs of State and Local Officials." Governmental Finance, Fall 1979.

3 Commission on Organization of the Executive Branch of the Government, Accounting and Budgeting (Washington, D.C.: U.S. Government Printing Office, 1949).

4 Allen Schick, Budget Innovation in the States, (Washington, D.C.: The Brookings Institution, 1971).

5 E. L. Enke, "The Accounting Preconditions of P.B.B.," Management Accounting, January 1972 , p. 34.

6 National Association of State Budget Officers, Survey of state Budget ing, 1979.

7 Graeme M. Taylor, "Introduction to Zero-Based Budgeting," in Contemporary Approaches to Public Budgeting, ed. Fred A. Kramer (Winthrop Publishers, Inc., 1979).

8 David W. Singleton, Bruce A. Smith, and James R. Cleveland, "Zero-Based Budgeting in Wilmington, Delaware," in Contemporary Approaches to Public

Budgeting , ed. Fred A. Kramer (Winthrop Publishers, Inc., 1979).

9 Statement 1, Governmental Accounting and Financial Reporting Principles, National Council on Governmental Accounting, Chicago, 1979.

10 NCGA Interpretation 10, "Statement and Local Government Budgetary Reporting," National Council on Governmental Accounting, Chicago, April

11 Statement 1. 